TAO, Vol. 14, No. 3, 343-367, September 2003

\title{
Investigating Near-surface Structures under the Changhua Fault, West-central Taiwan by the Reflection Seismic Method
}

\author{
Chien-Ying Wang ${ }^{1, *}$, Shen-You Kuo ${ }^{1}$, Wen-Li Shyu ${ }^{1}$, and Jui-Wen Hsiao ${ }^{1}$
}

(Manuscript received 1 April 2003, in final form 18 June 2003)

\begin{abstract}
The Changhua fault is a long fault $(80 \mathrm{~km})$, extending along the western border of three gravel terraces in west-central Taiwan. It represents the western-most thrust fault in the deformation front of Taiwan's western foothill area. Photogeologic studies indicate that it could be an active fault, as it has apparent lineation and fault scarps. In this study, we used the shallow reflection seismic method to map the near-surface structures around the fault and to examine its activity level. It is surprising to find that most of the seismic sections are composed of flat or slant layers and do not show significant traces of fault offsets. Combined with CPC data, we may categorize the fault as a 'blind-thrust' buried at the depth of $3 \mathrm{~km}$. Moreover, this long fault can be divided into northern and southern parts most likely separated by a hidden fault: the Tai-an fault. According to the layer bending attitude, the southern part of the Changhua fault (the Pakua terrace area) could be more active, and may still possess a certain degree of reactivity. By contrast, the northern part is relatively flat and quiet with low potential of activity. Besides detecting the Changhua fault, we also inspected its accompanying back-thrust faults: the Tiehchanshan fault and Hengshan fault, finding that they may not exist.
\end{abstract}

(Key words: Active Faults, Terraces, Taiwan Tectonics, Changhua Fault)

\section{INTRODUCTION}

After the 1999 Chi-Chi earthquake $(\mathrm{Mw}=7.6)$, knowledge about active faults has become an important issue of some public concern in Taiwan. The Chi-Chi earthquake induced extraordinarily large surface ruptures (as much as $10 \mathrm{~m}$ ) along the Chelungpu fault, and caused severe damage. According to the geology of west-central Taiwan (Fig. 1), there are four northsouth trending faults distributed from west to east: the Changhua, Chelungpu, Shuangtung,

\footnotetext{
${ }^{1}$ Institute of Geophysics, National Central University, Taiwan, ROC

${ }^{*}$ Corresponding author address: Prof. Chien- Ying Wang, Institute of Geophysics, National Central University, Taiwan, ROC; E-mail: wangcy@cc.ncu.edu.tw
} 


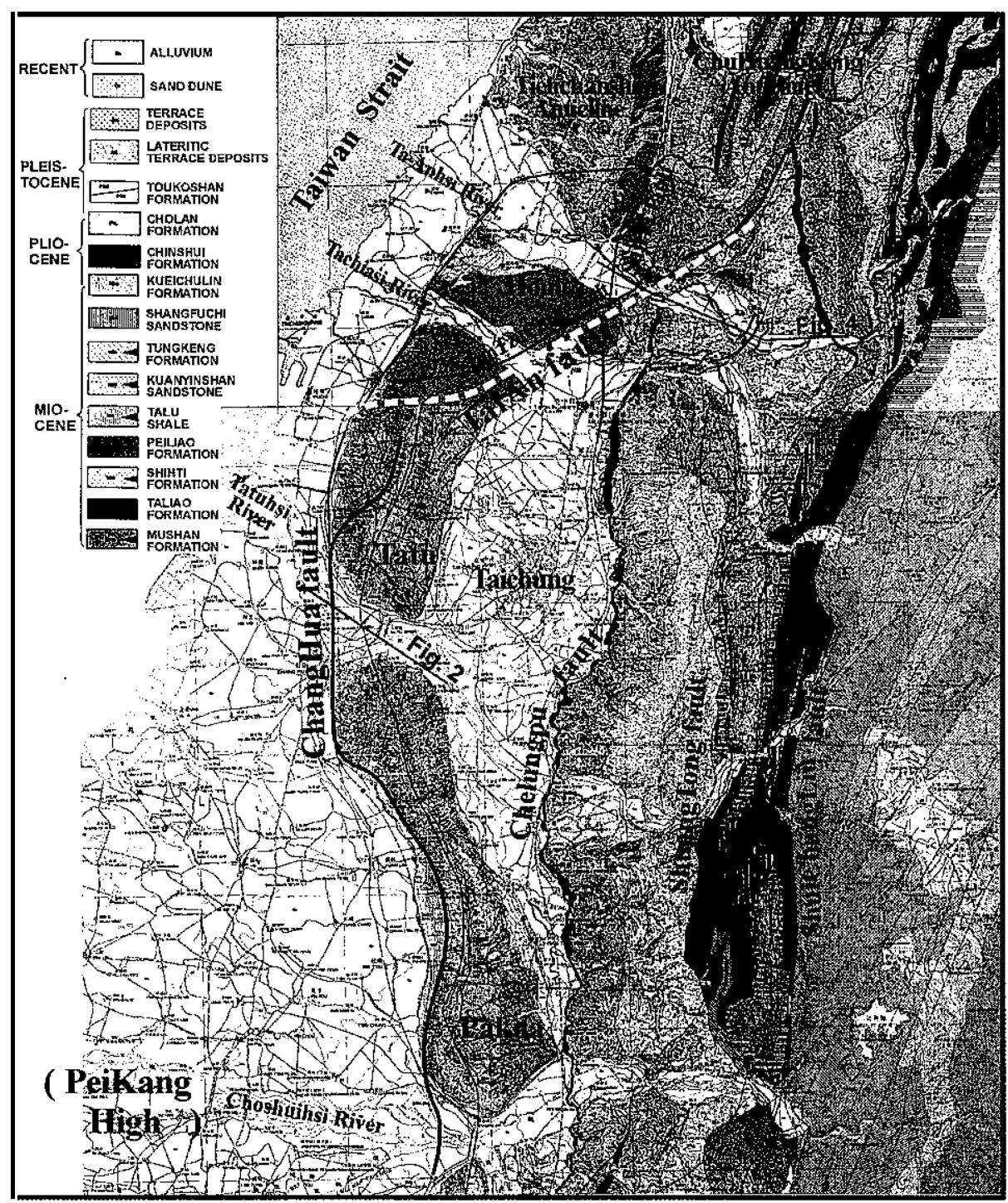

Fig. 1. The geological map of west-central Taiwan (adopted from the CPC 1982). The Changhua fault follows the western border of three lateritic terraces (from north to south): Houli, Tatu, and Pakua. Four major NS trending faults are denoted. Of these, the Chelungpu fault was activated during the 1999 Chi-Chi earthquake ( $\mathrm{Mw}=7.6)$; its western side is the Changhua fault, which is studied in this paper. The proposed Tai-an fault (white dashed line) cuts through the terraces in a NE-SW direction. This fault is located in a key position which could affect faults extending from south to north. The Tuntzuchiao fault, which was activated in the 1935 earthquake $(M=7.1)$, seems to have followed the trend of the Tai-an fault. 
and Shuichungliu faults, which represent sequential west-verge thrusts produced by the tectonic pushing from the east. Great worry has arisen that the Changhua fault might be the next to be triggered because of its closeness to the Chelungpu fault (Chi-Chi earthquake fault). Historically there was a damaging earthquake (estimated $M=7.1$ ) that occurred in the Changhua area in 1856, which caused more than 1,000 deaths (Tsai 1985).

According to the Central Geologic Survey (CGS 2001), the Changhua fault (originally named by the Chinese Perroleum Corporation, CPC) is composed of three aligned faults (from north to south): the Tachia, Chinshui, and Changhua faults. Of these, the Tachia fault belongs to the second class active fault (i.e., active after the late Pleistocene, or 10,000 years before present) and the other two are suspected faults (i.e., buried or unknown). These three faults extend along the western foot of three terraces, the Houli, Tatu, and Pakua terraces (Fig. 1). All these terraces are made of gravels covered by lateritic deposits. In this paper, we use the name 'Changhua fault' to represent these three aligned faults. The Changhua fault represents the western-most thrust along the deformation front in the foreland belt of western Taiwan (Ho 1988). Although some topographic lineation and fault-like scarps have been reported (Shih et al. 1986), outcrops of this fault have never been found. In fact, CPC seismic profiles reveal that a 'fault-bend-fold' system might more appropriately describe its underground structure (Fig. 2). The purpose of this study is to use the shallow reflection seismic method to map the near-surface structures around the fault and to examine its breakage status. This may provide reliable information for evaluating the reactive potential of the fault.

\section{GEOLOGICAL SETTING AND A BRIEF REVIEW OF CPC DATA}

Figure 1 shows the geological map of central Taiwan adopted from the CPC (CPC 1982). The three gravel terraces constitute the main feature to the west of the fold-and-fault foothill zone (the Chelungpu fault acts as a boundary). The Taichung basin is sited in between. Alluvial deposits, lateritic terrace deposits and the Toukoshan formation $(2-3 \mathrm{~km})$ cover the plain and terrace area. The Toukoshan formation contains two lithological faces: the lower one is dominated by fine to coarse grained sandstones and mudstones (Hsiangshan face) and the upper one is primarily composed of coarse-conglomerate deposits (Huoyenshan face). Above the Toukoshan formation are terrace deposits, made of thick unconsolidated gravel beds capped by a thin lateritic soil layer. The four main NS faults mentioned before are denoted on Fig. 1 . There is an additional fault, the Sanyi fault extending from the Chelungpu fault toward the north (Meng 1963). It is curious that most of the faults bend to the east at their northern ends (around or north of the Ta-anhsi and Tachiahsi rivers). It seems that there are significant structural variations under these 'two rivers'.

In the 1960's, the CPC explored central Taiwan, especially around the three-terrace areas, looking for natural resources of oil or gas. To the north of these terraces, there is a significant gas field, i.e., the Tiehchanshan anticline, which turned out to be the largest gas field ever found on Taiwan (Fig. 1). Dense seismic lines and gravity mapping were conducted, and several wells with depths greater than $1 \mathrm{~km}$ were drilled (Sun 1965; Pan 1967; Hsiao 1968; Chang 1971; Chou 1971; Yang 1972; Chiu 1975; Chen 1978; Suppe and Namson 1979; Hu 


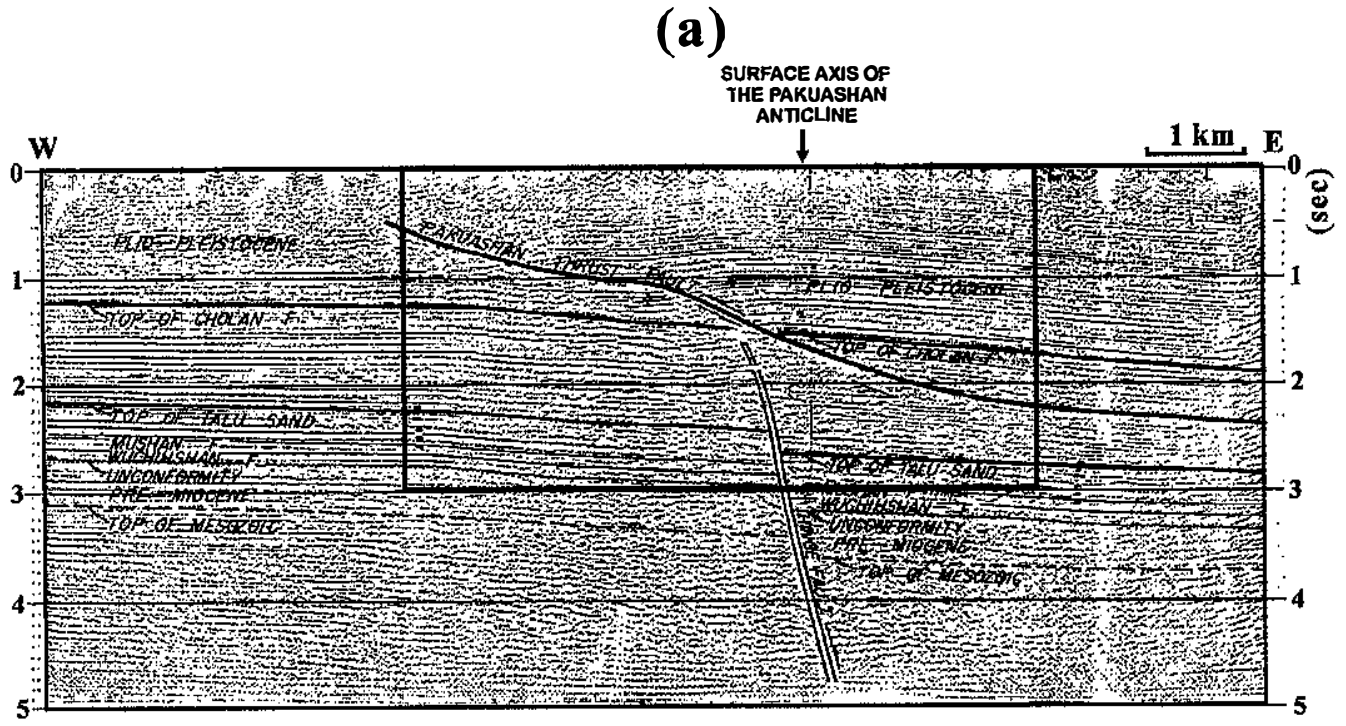

(b)

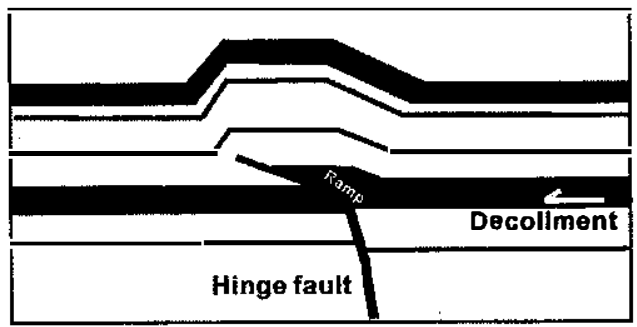

Fig. 2. (a) The fault-bend-fold structure under the Pakua-Tatu terraces proposed by the CPC researchers (Hsiao 1968; Chen 1978), based on their seismic and borehole data. A conceptual model (b) is derived in this paper. A hinge fault is placed under the terrace and above it a shallow thrust developed at the front edge of this deformation system. The fault, named the Pakuashan thrust fault here, is equivalent to the Changhua fault, which is actually a blind thrust. No structural offset near the surface caused by the Changhua fault is visible on the seismic section.

and Chiu 1984). Although the exploration results were unproductive, the effort produced lots of data about central Taiwan. The main reason for the unsuccessful exploration was that the young Pleistocene and Pliocene layers were too thick ( $>3 \mathrm{~km}$; see Fig. 3 ) and the Miocene rocks (potential gas deposit layers) were too thin or too deformed.

The three terraces in west-central Taiwan represent underground structural deformations that developed within the Taiwan tectonic region. Tectonic pressure from the east may interact with the Peikang basement high, located southwest of the Pakua terrace (Fig. 1). Although the 
subduction of the Eurasian plate toward the east under the Taiwan island is not certain nor has it been observed, the obstacle effect of the Peikang High is apparently causing the structural deformation around it. Figure 2a shows a representative seismic section of the area (along the Tatuhsi river; see Fig.1 for the location; Chen 1978). This section clearly illustrates a buried blind-thrust fault under the terraces. This blind-thrust could be a deep old hinge fault which would account for structural variations between the piggy-back Taichung basin and the rising front terraces. Perhaps in the late Pliocene, this hinge fault acted as a normal fault, causing the Taichung basin to sink on its eastern side and depositing a thick gravel layer $(3 \mathrm{~km})$. The center of this basin might be along the Wuhsi river, which produced a Bouguer gravity anomaly low at the town of Wufeng (Fig. 3). The Wufeng gravity low is actually the lowest on the Taiwan island (-64 mgal), which implies that substantial subsidence has occurred. As Taiwan's tectonic movement became more active during the Pleistocene, tectonic compression made the fault reverse and become a thrust fault that uplifted the three terraces. It is apparent that the hinge fault changed its role, becoming a ramp, causing a 'fault-bend-fold' structure to develop (Fig. 2b; Suppe 1981).

Figure 3 shows the Bouguer gravity anomaly map and an interesting NS structural profile sketched in the study area. The gravity map is adopted from Pan (1967) and the NS profile from Chang (1971), with a rough geological map overlapped. This NS profile indicates that the Miocene rocks become thinner in the south, apparently affected by the Peikang High. On the other hand, the thicknesses of the Pliocene and Pleistocene layers are quite uniform. The structures start to rise north of the Houli terrace before they enter the Tiehchanshan anticline gas field. Two wells (PKS-1 and PKS-2) at the northern corner of the Pakua terrace has been drilled into a structural high, called the Huatan Culmination by Chang (1971). This is an important structural undulation, which will be discussed more later. On the gravity map, an abrupt change of contour densities occurs in the northwest region. A NE-SW trending dashed line separates the high and low gravity gradient regions on Fig. 3. We suspect that some structural boundary may exist along this line. We assume this to be a buried fault: the Tai-an fault, proposed by the CPC geophysicists (Chen and Su 2002) to account for such a pattern change. A surface fault trace (dominantly strike-slip) from the 1935 Hsinchu-Taichung earthquake (M = 7.1), the Tungtzuchiao fault (Fig. 1), parallels to the Tai-an fault across the Houli and the northern Tatu terraces. The Tungtzuchiao fault could be a surface mark reflecting the effect of the buried, primary Tai-an fault.

Figure 4 shows an important, widely referred to, CPC seismic section (Hu and Chiu 1984; Hung and Wiltschko 1993; Lee et al. 2002; Wang 2002). This seismic profile follows the Taanhsi river at the position shown in Fig. 1. The two-way time at 2 sec corresponds to about 3 $\mathrm{km}$ in depth. A buried Tai-an fault is substantially indicated as a big thrust system under the Sanyi fault which slides at shallower depths. It is obvious that the Tai-an fault forms a ramp on which the Sanyi structures thrust. This Tai-an fault dips by 70 degrees toward the NW, with the NW side being a hanging wall. The existence of this buried fault has been confirmed by the CPC's KTS-1 well. A large offset of $1400 \mathrm{~m}$ has been reported (Chen and Su 2002).

The respected CPC geologist, Dr. C. Y. Meng, has argued that an EW ransverse structure may exist along the two rivers (Meng 1965). He believed that this boundary would form a barrier that would hinder the gas field from migrating to the south, i.e., into the Taichung area. 


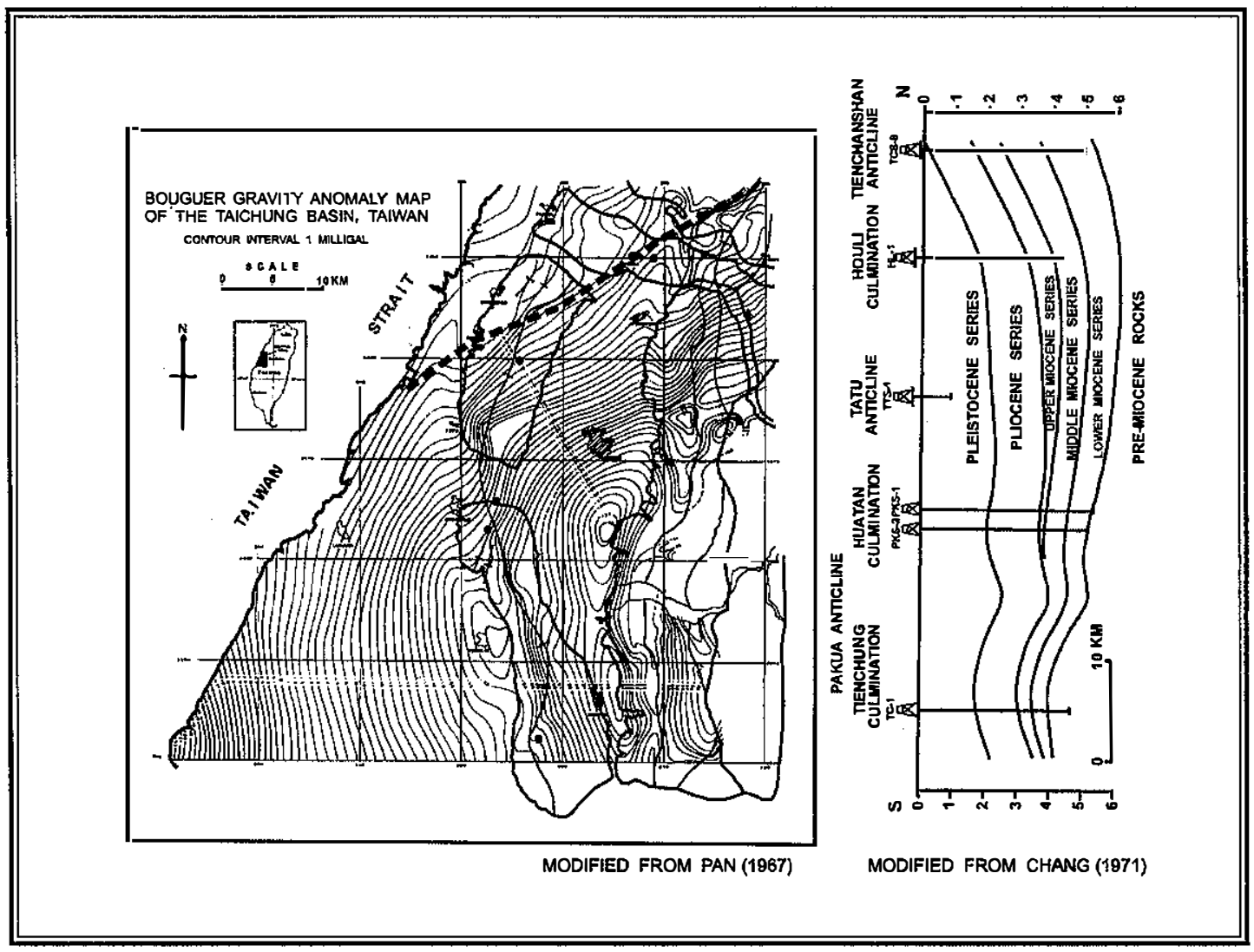

Fig. 3. The Bouguer gravity anomaly map and a NS profile in the central Taiwan region (adopted from Pan 1967 and Chang 1971). An abrupt change of contours occurs in the northwest. The dashed line trending NE-SW separates the high and low gravity gradient regions (i.e., the buried Taian fault). Two structural highs (the Tienchung and Huatan culminations) are identified to the south. The structure arises north of the Houli terrace, then enters the Tiehchanshan anticline region in the north.

We too found that all the structural variations in and near the 'two-river' area, such as the fault's bending to the east, the gravity gradient changes, the layer's rising toward the north, are implications of this transverse structural boundary. This transverse structure may have deep foundations occupying a wider region. The Tai-an fault could be a part of this transverse system.

\section{METHOD, FIELD WORK AND DATA PROCESSING}

The shallow seismic reflection method is used to map shallow structures related to the fault. It not only describes the geometric features near the fault, but also the general geological 


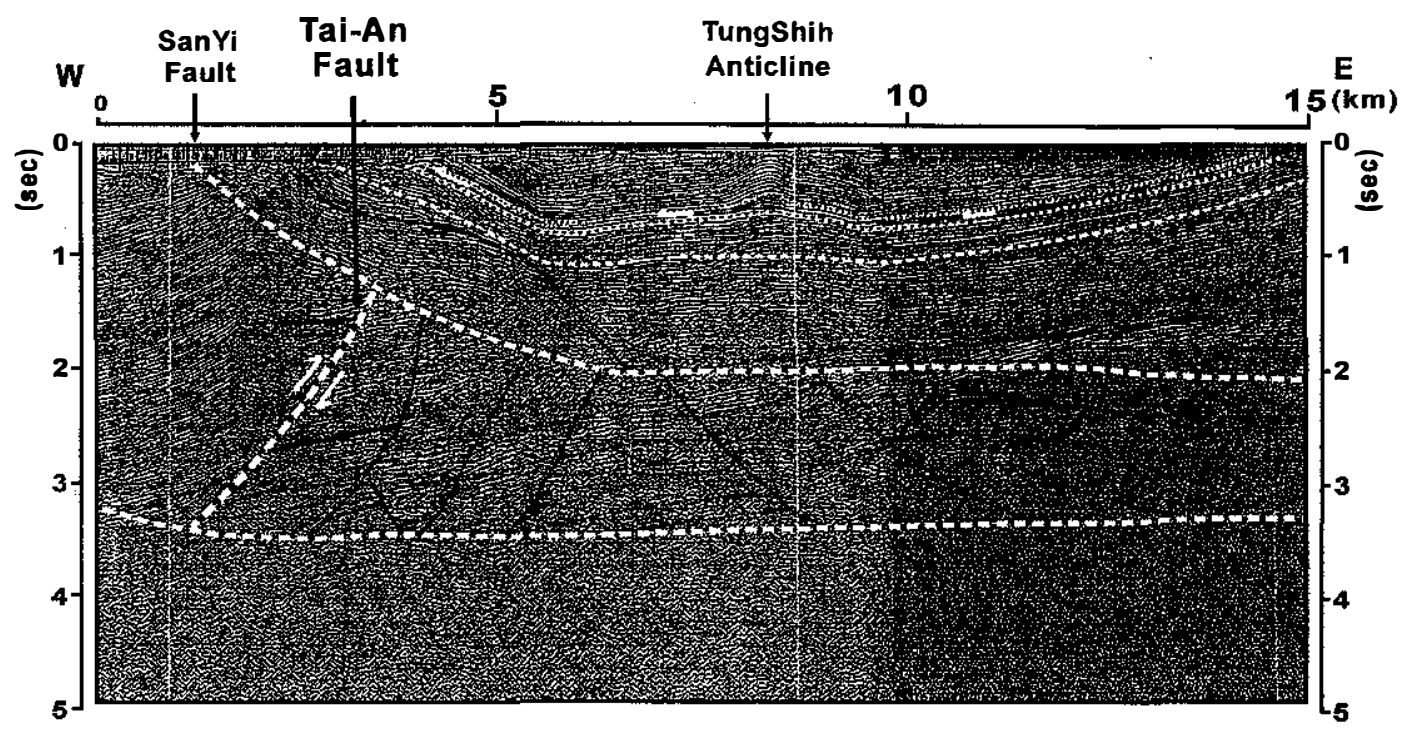

Fig. 4. A widely referred to CPC seismic section. This seismic line follows the Ta-anhsi river in the position shown in Fig. 1. The buried Tai-an fault substantially indicates a big thrust system under the Sanyi fault which slides at shallow depths. It is obvious that the Tai-an fault forms a ramp, on which the Sanyi thrust structures have developed.

structures which may affect the fault (Wang et al. 2001). Here we define shallow reflection seismics according to the survey size (hundreds of meters), as compared to the large-scaled (tens of kilometers) oil exploration surveys. In addition, we propose that the shallow seismic method can be further subdivided into two kinds: 'very-shallow' and 'shallow' types. 'Veryshallow' seismics may target a depth range 'as shallow as possible', say less than $200 \mathrm{~m}$, for the purposes of engineering applications. 'Shallow' seismics, on the other hand, reaches depths 'as deep as possible', say $2000 \mathrm{~m}$, and is used for structural mapping. The frequency band is one factor that distinguishes these two small-scaled seismics types. 'Two hundred' $\mathrm{Hz}$ is a good separation point when the earth filtering effect and background noise are taken into consideration. For 'very-shallow' seismcs, high frequency sources (gun shots, sparks, etc.), receivers (accelerameters), and small survey sizes (tens of meters) are involved to explore detailed near-surface structures. In contrast, 'shallow' seismics can be thought of as a branch of oil-exploration surveys, but using smaller instruments, budgets, and less man-power, for the sake of efficiency and economic limitations. 'Shallow seismics' can be used a tool to study near-surface structures in regular geologic mapping. In this paper, we will explore the ability of the 'shallow' seismic method, to map the structures of a relatively large area.

Standard CDP shooting techniques were applied in the field work. The equipments used were; 1) source: EWG-III weight drop impact pulse generator, 2) receiver: OYO $40-\mathrm{Hz}$ geophone, 3) recorder: DAS-1 96 channel seismograph. The parameters used to collect the data were; 1) source interval: $6 \mathrm{~m}, 2$ ) receiver interval: $2 \mathrm{~m}, 3$ ) near-offset: $100 \mathrm{~m}, 4$ ) fold: 16 , 
5) sampling rate: $0.25 \mathrm{msec}, 6$ ) low-cut filter: $40 \mathrm{~Hz}$. Most of the field work was carried out at night time to avoid traffic noise. The data processing followed the standard CDP data processing procedures, except for emphasizing some dip filters and static corrections. The survey area had strong groundroll, so a combination of longer near-offsets and different kinds of filters was necessary. For the static correction, we applied the specially designed refraction statics to treat the near-surface irregularities. Such correction is very important in shallow seismics due to its sensitivity to small anomalies.

The positions of the seismic lines (total 66) are shown in Fig. 5. (For more details, check Hsu 2001 and Hsiao 2002.) They are grouped into 11 profiles (from A to K). Of these, 2 profiles (A and $\mathrm{B}$ ) are on the Houli terrace, 6 profiles ( $\mathrm{C}$ to $\mathrm{H}$ ) on the Tatu terrace, and 3 (I to $\mathrm{K}$ ) on the Pakua terrace. Each profile contains 3-11 sections, which are more or less aligned. Except for some sections which directly detect the fault (e.g., profiles $\mathrm{C}$, J and $\mathrm{K}$ ), most sections are $500 \mathrm{~m}$ long ( 33 shots) and located about $1 \mathrm{~km}$ apart. By aligning the sections in a row, we can trace the key beds and determine structural relations along the profile. This kind of seismic survey, known as 'wide-spread' seismic lines (Wang et al. 2001), has been proven useful for effectively mapping structures in a relatively large area. This technique can be used to detect a fault as well as investigate its structural insights, and is thus worth recommending for the study of active faults.

\section{RESULTS}

\subsection{The Houli Terrace and the Northern Tatu Terrace}

Using the Tai-an fault as a dividing boundary, we can separate the Changhua fault into two parts (Figs. 1 and 5). The northern part contains the Houli terrace and the northern portion of the Tatu terrace, which has the Tachiahsi river in between. The southern part consists of the southern portion of the Tatu terrace and the Pakua terrace, which brackets the Tatuhsi river. We will discuss the seismic sections along the Changhua fault from north to south. The locations of all seismic lines are depicted in Fig. 5. Most are oriented in an east-west direction perpendicular to the major structural trend. The topography shown in Fig. 5a also indicates that the northern Tatu terrace and the Houli terrace could be in a same system. The structures on two sides of the Tachiahsi river have been found not possessing much difference (Chang 1994). These structures were developed north of (or behind) the Tai-an fault.

First, let us check the seismic section adopted from an oil-exploration survey (Chen and Su 2002). Only the upper 3 seconds are shown (Fig. 6). This profile, A, is an EW seismic section taken along the central axis of the Houli terrace (Fig. 5a). A low relief anticline is observed in the western half, which may represent a southern extension of the Tiehchanshan anticline. The Changhua fault is cautiously expected to be located at deeper places, but the seismic signals there are not good enough to ascertain whether this is the case. A shallow seismic section $A^{\prime}$, overlapping a small portion of section A, is also shown in Fig. 6. Both sections have similar small westward dipping angles of layers (less than 10 degrees) here. Most outcrops in Tiehchanshan (a peak near the town of Tachia; Fig. 1 or Fig. 5a) show dip angles between 6 and 12 degrees, which agree with seismic results. Since the dip angles are 
too small, it seems unlikely that there is a NS anticline axis on the Houli terrace (CPC 1982; Chang 1994). The layers under the western half of the Houli terrace are apparently flat. Moreover, there dose not have any hint of layer irregularities at possible positions of the Tiehchanshan fault (marked by a ' ?' symbol in Fig. 6). This structural layer flatness under the Houli terrace is also consistent with the slow varying gravities that have been shown in Fig. 3 .

On the eastern half of section A, the Tai-an fault assuredly can be assigned with the same dipping angle as in Fig. 4. Here the Tai-an fault is closer to the surface. Nevertheless, both Changhua and Tai-an faults are covered by shallow deposits above 1 second, probably, of the Toukoshan formation. The Houli terrace is actually a structural flat region, although its uneven surface may have been greatly shaped by the erosion from two rivers.

The oil-exploration seismic section A can next be compared with shallow seismic profile B (Fig. 7). Although the resolution power is different, they actually reveal similar underground information above 1 second. Profile $\mathrm{B}$ contains a series of sections made along the southern border of the Houli terrace, also at the northern bank of the Tachiahsi river (Fig. 5a). This is a typical example of a 'wide-spread' seismic line distribution. The quality of each section is surprisingly good; they have identifiable seismic reflection images through out the whole depth, about $1800 \mathrm{~m}$ ( $1 \mathrm{sec}$ long). These two profiles, $\mathrm{A}$ and $\mathrm{B}$, are about $3 \mathrm{~km}$ apart. We can see that the layers swing slight up-and-down, forming a small-amplitude anticline. On profile B (Fig. 7), however, the shallow seismic data show clearer and higher dipping angles on the western wing (B3, about 12 degrees). It is quite obvious that the structural layers are bent but not broken at the suspected Changhua fault position. Moreover, the layer dipping angles may be subdued toward the north (compared with section A').

A back thrust structure accompanying the Changhua fault, on either side of the Tachiahsi river, named the Tiehchanshan-Hengshan fault has been widely discussed in documents (Shih et al. 1986; Chang 1994; Chang and Yang 2001). It has apparent geomorphologic features such as scarps, ground depressions, etc., (see Fig. 5a). To investigate the Changhua fault and this back thrust fault, we shot a long line, C ( $2 \mathrm{~km}$ long; Fig. 8), at the southern bank of the Tachiahsi river near the town of Chianan (Figs. 5a and 8). Surprisingly no fault offsets can be found on this section. The layers vary smoothly and continuously. The bending of layers in the western part of the section are of the same type, and possibly from the same cause (blindthrust), as those shown in Figs. 6 and 7. A dip angle of 10 degrees was measured. However, the eastern part becomes quite flat. We cannot find any trace of structural ruptures except that in the upper-right-hand corner, where buried water channels are obvious. The section in Fig. 8 is long enough to cover the possible positions of the suspected back thrust. Profile D in Fig. 8 provides further controls to the south. Using these and the CPC section in Fig. 6, we propose that the suspected Tiehchanshan- Hengshan back thrust fault may not exist. The corresponding depression on the surface could be just a kind of erosion valley, quite probably following the old water pathways as implied by the buried channels observed in the section. The seismic results do not favor the existence of a Tiehchanshan- Hengshan fault.

\subsection{The Southern Tatu Terrace}

On the landscape of the Tatu terrace, there is an open depression in the middle of its 
(a)

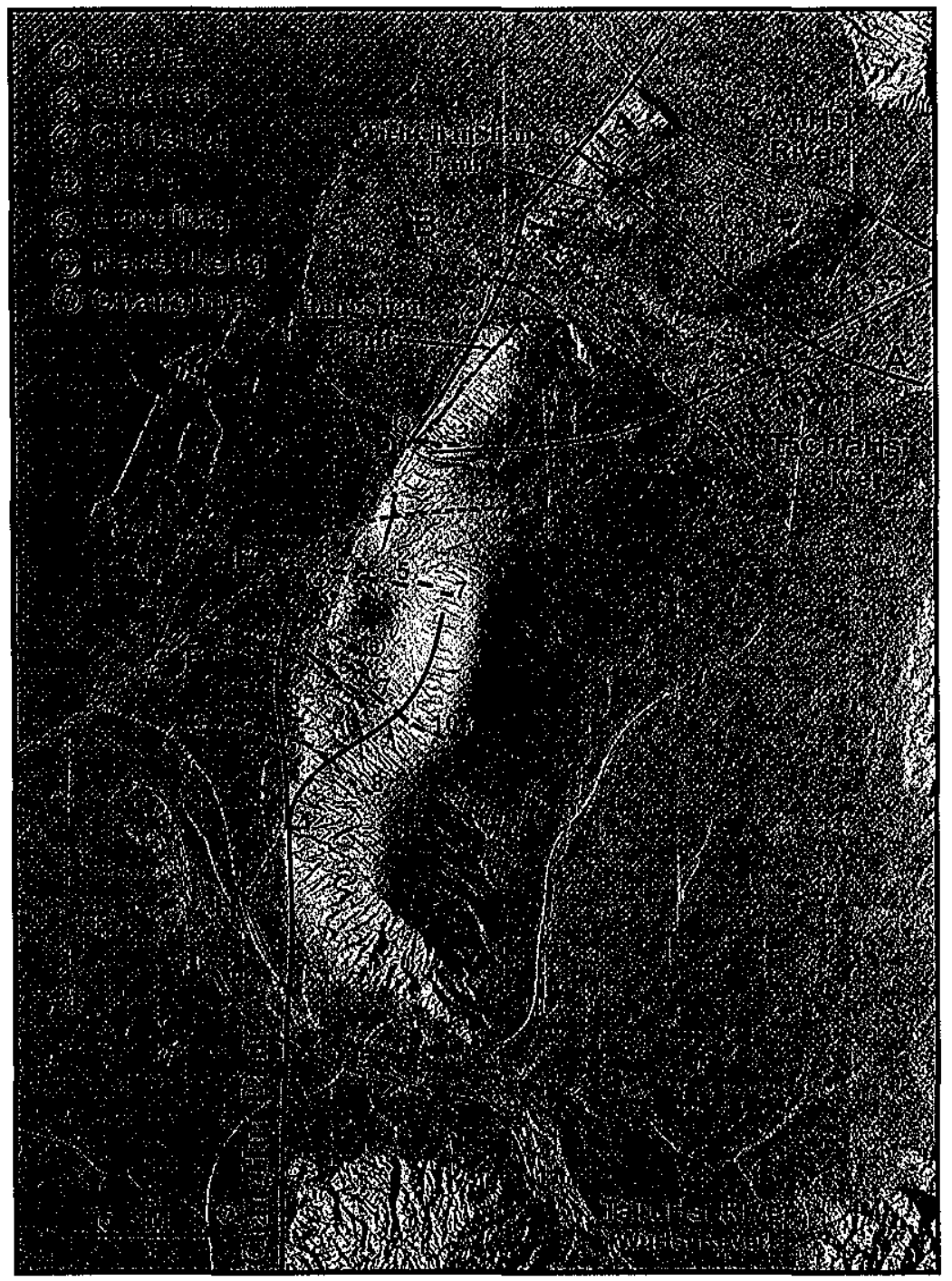

Fig. 5. The shaded DTM images of three terraces in west-central Taiwan: (a) is the Houli and Tatu terraces and (b) is the Pakua terrace. 11 groups of seismic lines (A to $\mathrm{K}$ ) are plotted. The Changhua fault, denoted by solid lines, is bisected by the Tai-an fault (dashed line) as seen in (a). A possible backthrust: the Tiehchanshan-Hengshan fault, to the east of the Changhua fault, has sharp geomorphic characteristics. (b) shows the symmerric Pakua terrace in the north, but the symmetric axis shifts to the west in the south. The names of towns referred to in the text are also indicated. 
(b)

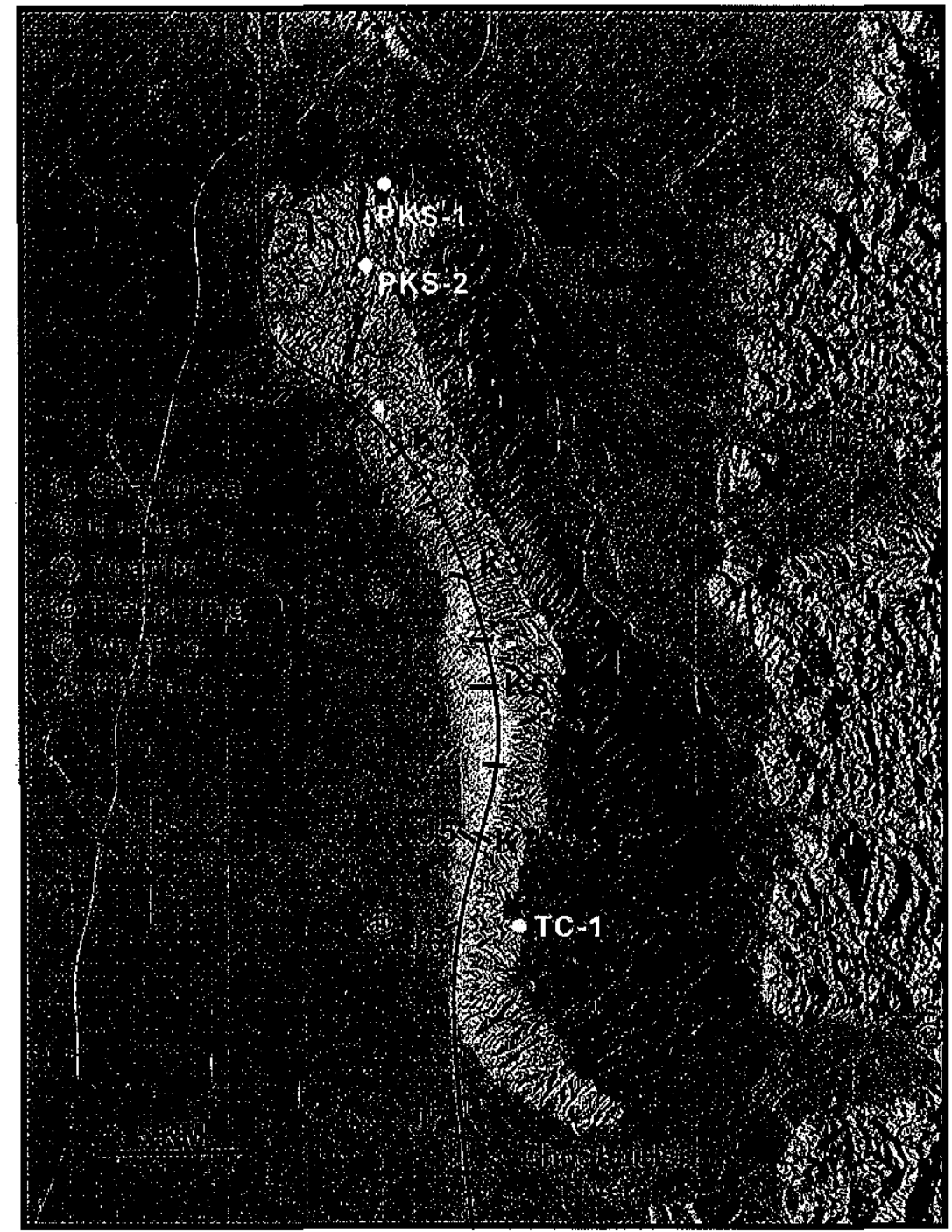

Fig. 5. (Continue)

western border region between Shalu and Lungjing (between E and G in Fig. 5a), called the Nansukeng depression area. This makes the major ground uplifting shift from the hill's foot to the east by $4 \mathrm{~km}$. We argue that this could be a blocking effect due to the transverse Tai-an fault. Three long profiles E, F, and G, each containing 7-10 sections, were made across this depression area. This was a tough work, since the area is heavily habited and the field work is not easy to perform at the night time. Figures 9,10 and 11 show these three long profiles. Their locations are given in Fig. 5a. 


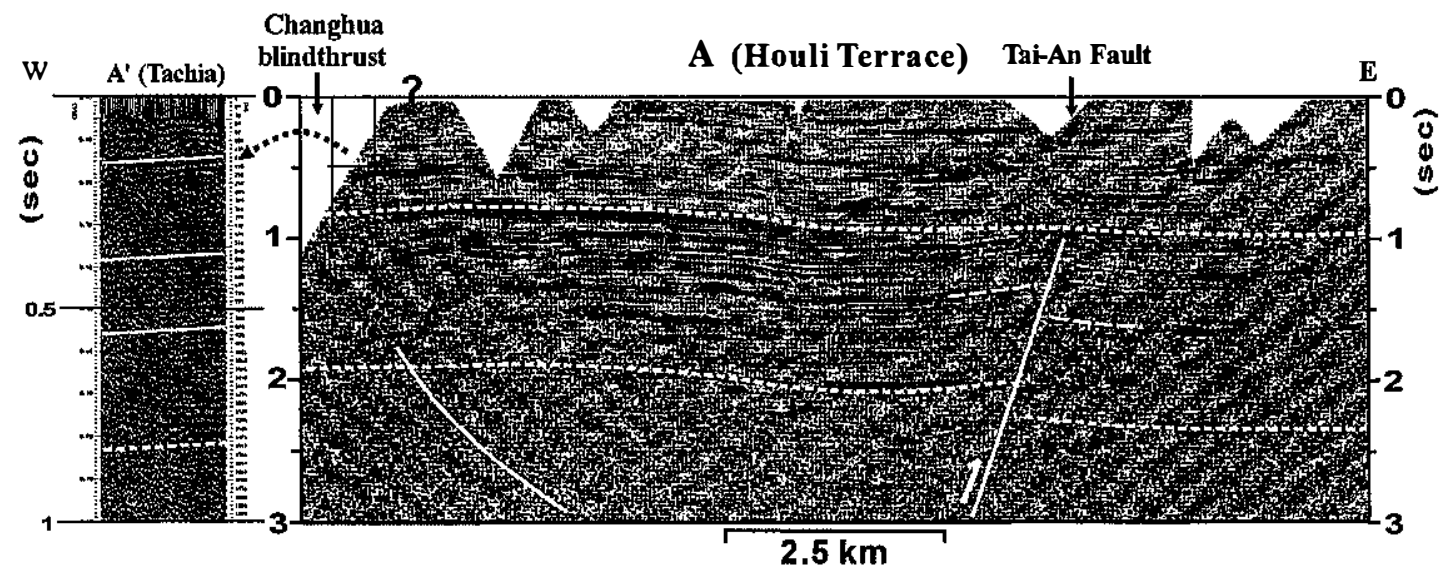

Fig. 6. An EW seismic section, A, made along the central axis of the Houli terrace (adopted from Chen and Su 2002). Section A' is a shallow seismic section which covers a small portion of $\mathrm{A}$, but has much higher resolution. Check Fig. 5a for locations. These seismic sections, and all other sections, in this paper have been plotted using approximately the same horizontal and vertical scales. The Tai-an fault may have been raised to the 1-sec depth, but it is covered by shallow deposits. The layers on the west are bent but not broken, which implies a buried Changhua fault. The layers dip quite gently in this profile.

Figure 9 shows profile E, which ansects the middle of the Tatu terrace near the town of Shalu. It was not anticipated that the structural layers are 'surprisingly flat' in this profile. It seems that the seismic line crosses a 'quiet' region with little structural disturbance. There is just a small kink, probably between the E4 and E5 sections. This 'flat', 'quiet' structure was totally unexpected, considering the layer bending that the Changhua fault might have produced. We suspect that stress system adjustment may have occurred in this area, perhaps due to the interaction of the Tai-an fault system and the Changhua fault system (Fig. 5a). It is known that the Tai-an fault steps down toward the south, which may be deeper and older. However, the Changhua fault thrusts toward the northwest, perhaps ascending above the Tai-an fault. This ascending feature may have been 'healed' by the opposite step already there on the Tai-an fault. It is quite possible that this 'healing' effect may have reduced layer bending, resulting in the flat structure seen in Fig. 9.

Further south, the structures again undulate, as that shown in profile F (Fig. 10). This profile crosses the center of the Nansukeng depression area (Fig. 5a). A low-relief anticline, with its axis following the border of the Tatu terrace (F4 position in Fig. 5a), shows up on the western half. The layer-bending at the western wing $(\mathrm{F} 3)$ could be due to a northern extension of the Changhua fault. However, to its east, a wide syncline develops, the Nansukeng syncline (F5 to F10). On the eastern wing, the layer bends to make a larger slope, possibly the main fold caused by the Changhua fault (Fig. 5a). Hence, there are two branches of the Changhua fault in 


\section{B (TaChiaHsi)}
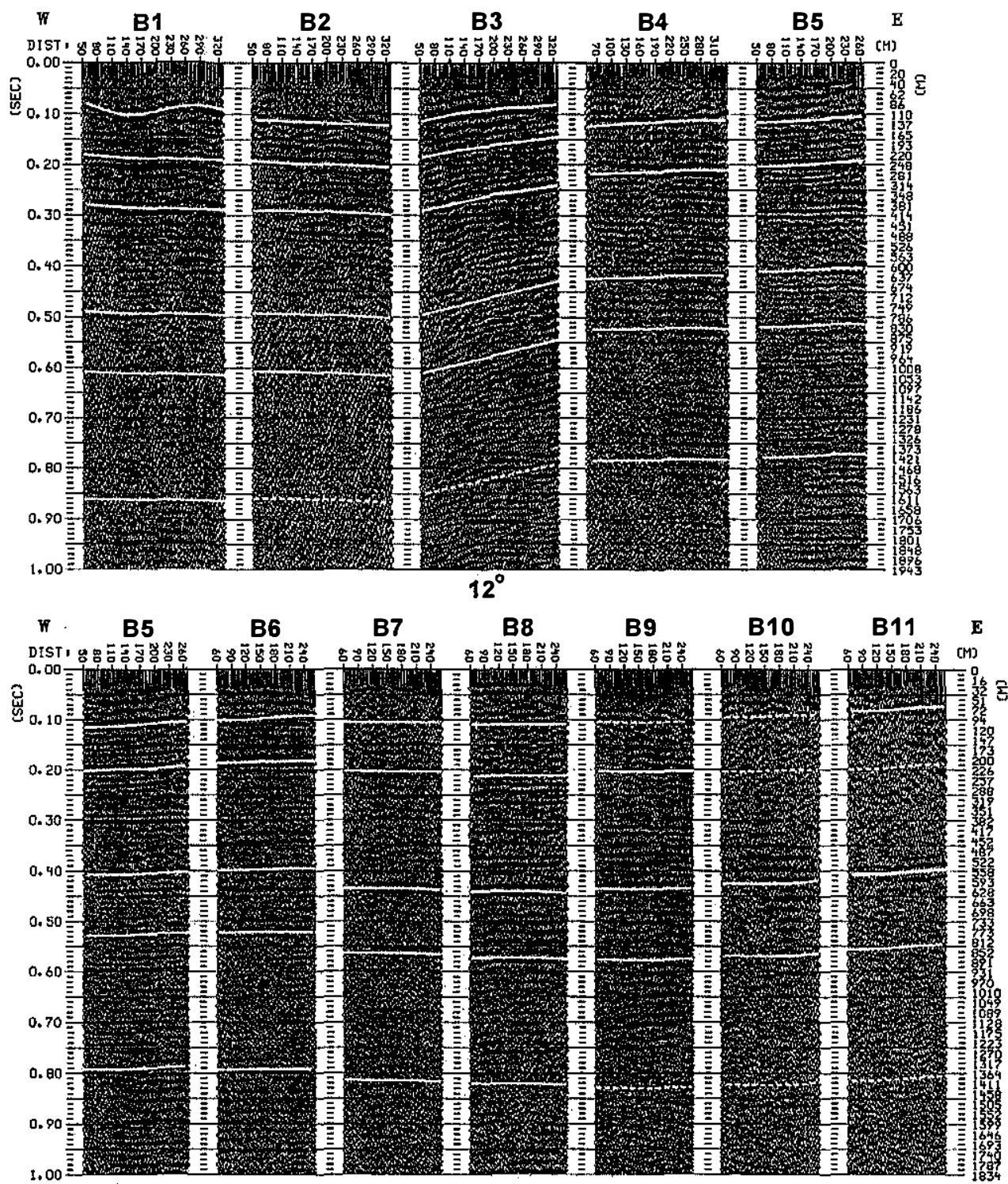

Fig. 7. Seismic profile B follows the southern border of the Houli terrace, or equivalently the northern bank of the Tachiahsi river. This profile consists of 11 sections in a line. The layers are quite flat in most of the sections, except at the expected Changhua fault position (B3), which shows a dip angle of about 12 degrees. This profile is quite similar to that in Fig. 6, although different parts of the subsurface structures exhibit different details. 

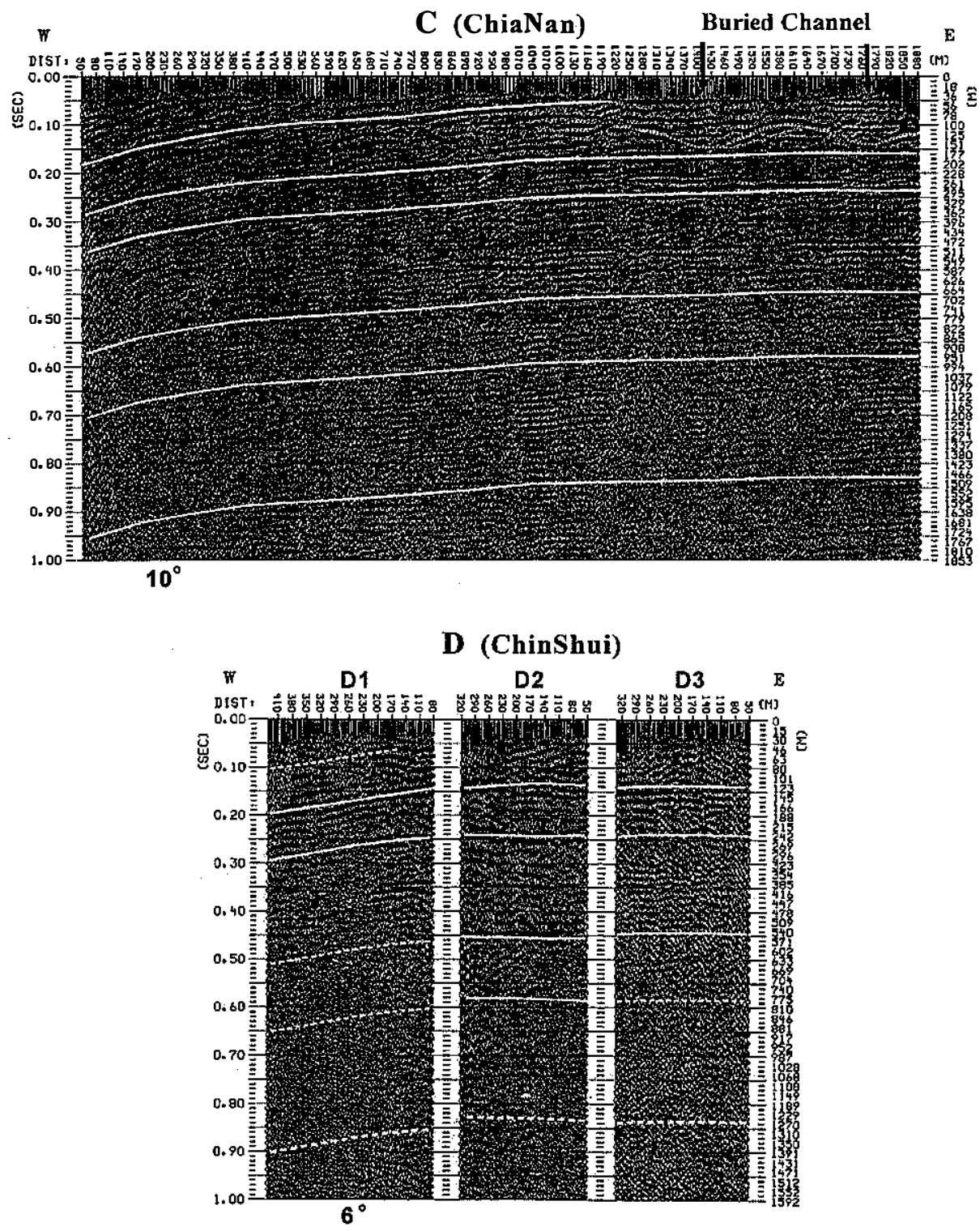

Fig. 8. A long profile C ( $2 \mathrm{~km}$ long)taken along the southern bank of the Tachiahsi river, used to detect not only the Changhua fault, but also the accompanying backthrust: the Tiehchanshan-Hengshan fault. The bending of the layers in the western half may be caused by the deep Changhua thrust. However, on the eastern half, only buried water channels appear, as seen in the upper-right corner, and the deeper layers are apparently flat. No clue of the Tiehchanshan-Hengshan backthrust is visible. Profile D (to the south of $\mathrm{C}$ ) does not show significant fault traces, either. 
E (ShaLu)
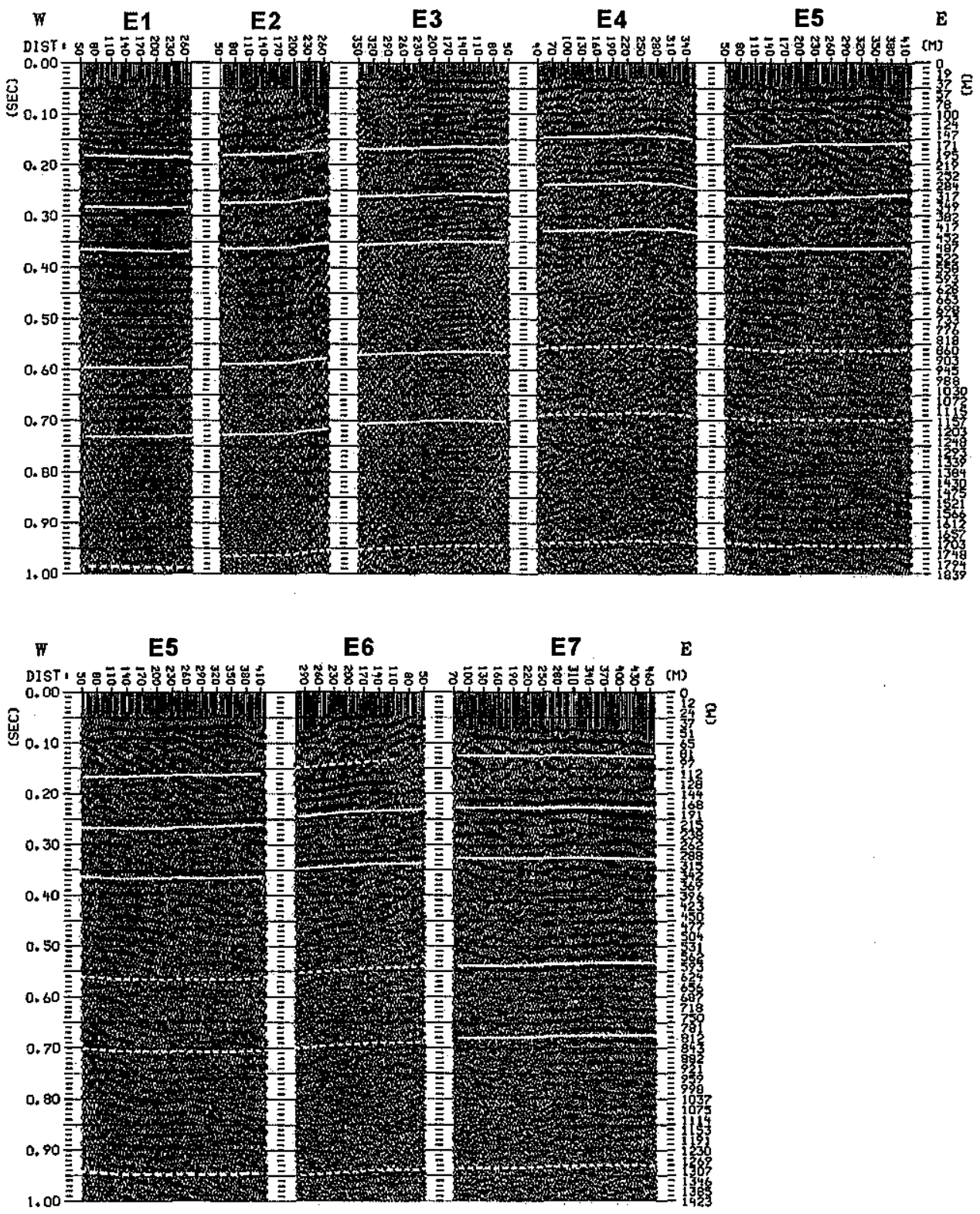

Fig. 9. Seismic profile E transects the middle of the Tatu terrace near the town of Shalu. One surprising feature about this profile is its relatively flat layers. This 'flat', 'quiet' structure implies that there might have a structure system change in this area, perhaps due to the interaction between the Tai-an fault and Changhua fault systems. 


\section{F (NanSuKeng)}
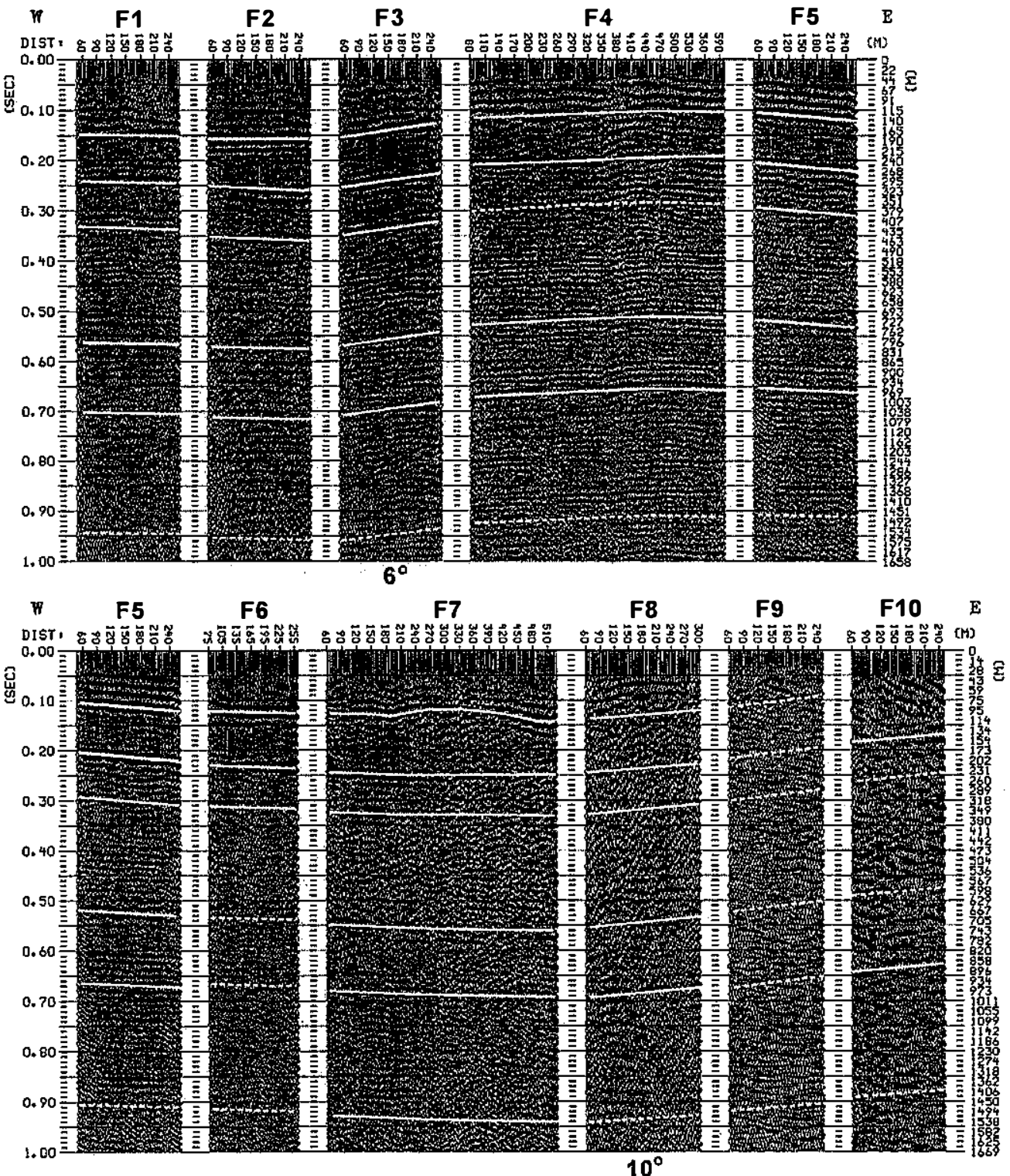

Fig. 10. Seismic profile F made across the Nansukeng depression area. A lowrelief anticline shows up in the middle and on both sides two synclinelike depressions appear. The bending of the eastern layer (F8 to F10) could be the major fold caused by the deep Changhua fault with the western (F3) being a minor branch. Such branching is suspected to have been caused by the 'blocking effect' induced by the Tai-an fault. 

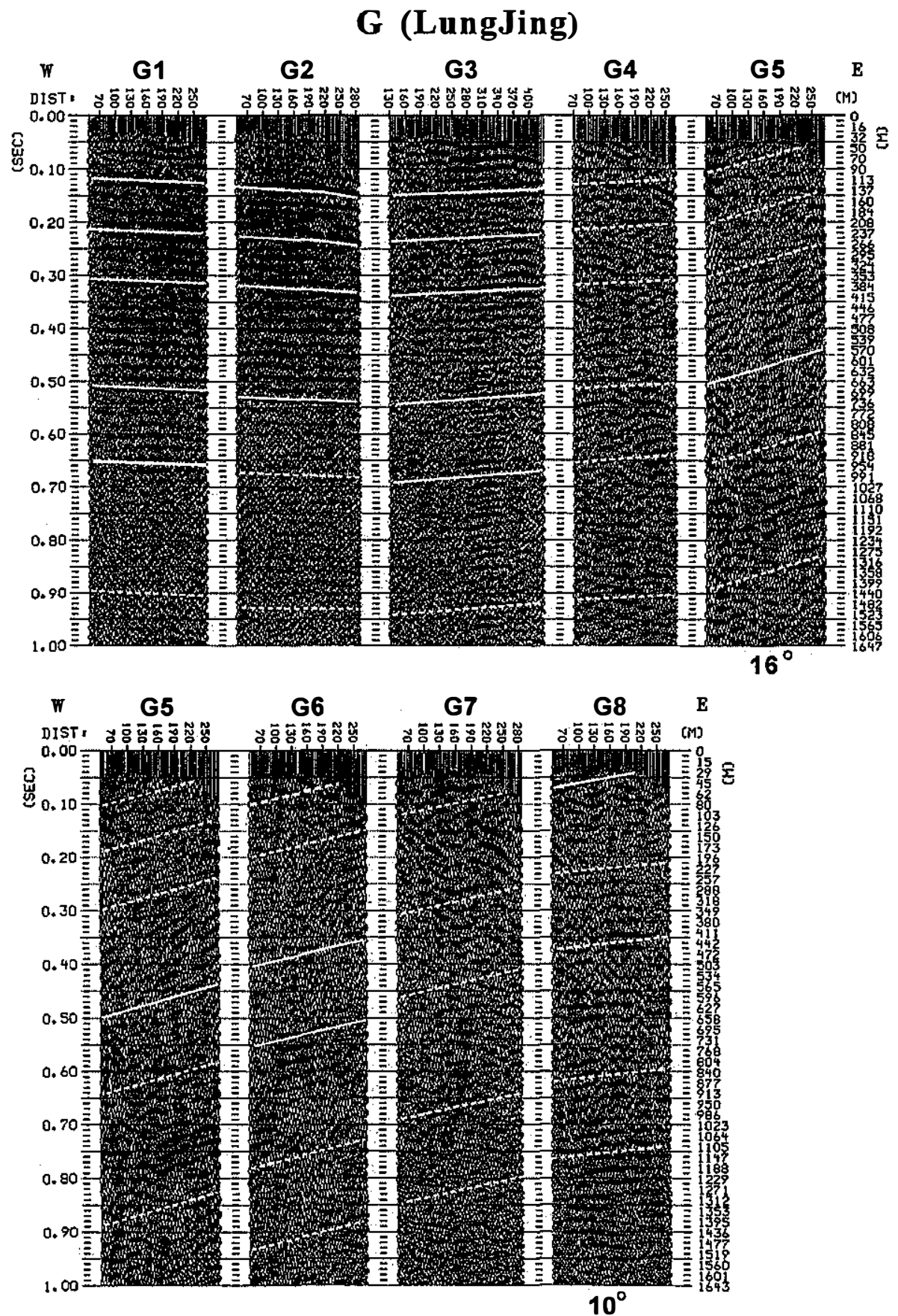

Fig. 11. Profile $\mathrm{G}$ in the Lungjing area. The rising of layers east of the $\mathrm{G} 4$ section indicates the apparent position of the deep Changhua fault. This can be connected to the major fault position in Fig. 10. 
this area. We still attribute this branching to the 'blocking effect' of the Tai-an fault. One thing worth pointing out is that the surface slope along the F6 and F7 sections ascends toward the east, but the underground structures dip in an opposite way, i.e., it descends. This type of behavior is quite rare for an active fault in Taiwan. One explanation is that the fold may be so old that its surface conditions have been largely modified, leading to this inconsistency.

Two other southern profiles, $\mathrm{G}$ and $\mathrm{H}$ (Figs. 11 and 12), show relatively large structural layer dipping angles (about 15 to 25 degrees) along the suspected Changhua fault positions. The angles become higher moving to the south. The Lungjing profile (G) shows a simple rising to the east, which forms the western wing of the Tatu anticline. This agrees well with the surface topography. Further south, the two $\mathrm{H}$ profiles reveal steep dipping layers before crossing the Tatuhsi river to the Pakua area where even higher angles are found. The consistently increasing dip angles imply that the structures on two sides of the Tatuhsi river are in the same system.

\subsection{The Pakua Terrace}

The Pakua terrace and the Tatu terrace lie side by side (Fig. 5) with the Tatuhsi river in between. There is a NS anticline passing through the middle of both terraces, although the Tatu anticline may terminate before meeting the transverse Tai-an fault to the north (Fig. 1). The relationship between these two terraces has been a topic of interest among researchers. (Lee et al. 1996; Delcaillau et al. 1998; Mouthereau et al. 1999; Delcaillau 2001)

Profile I (Fig. 12) was made along the Tatuhsi river, and actually had the same location as the CPC section shown in Fig. 2a (Chen 1978). However, many more details are visible in this shallow seismic profile. An asymmetric anticline is quite obvious. The western wing is much steeper with a dipping angle of as much as 30 degrees. This is no doubt the result of one-sided compression from the east. A gross model of the compression processes is illustrated in Fig. $2 \mathrm{~b}$; a 'fault-bend-fold' mechanism is used to explain the creation of the tilted anticline at the front on top of a blind thrust fault. Moreover, Fig. 1 indicates that the surface path of the Changhua fault on the two sides of the Tatuhsi river is symmetrical (when its bending to the east at Lungjing is considered). It may not be too unreasonable that there is a local compression center at the Tatuhsi river, that could account for the large compressions causing the high anticline uplift. Accordingly, the structural high at Huatan (i.e., the Huatan culmination in Fig. 3) proposed by Chang (1971) may need to be shifted a little north, and renamed the Tatuhsi culmination. It is quite possible that this structural high may be split at its apex allowing the Tatuhsi river to flow through. Chen and $\mathrm{Ho}(2000)$ have pointed out such a structural variation.

Figures 13 and 14 respectively show the seismic sections collected in the plain area (profile $\mathrm{J}$ ) and on the hill (profile K) at the western border of the Pakua terrace. Their positions are indicated in Fig. 5b. Most of the $\mathrm{J}$ sections were purposely located at the position of the Changhua fault suggested by the CPC (Fig. 1). However, the underground layers were found flat, so, the fault may not extend in the plain area. We next moved the survey lines to the east along the boundary between the high and low level terrace surfaces at the positions proposed by Shih et al. (1986), i.e., at the Yuanlin and Tienchung faults. Figure 14 shows the sections of profile K. The seismic signals in this profile are not good due to the presence of steep surface slopes and 


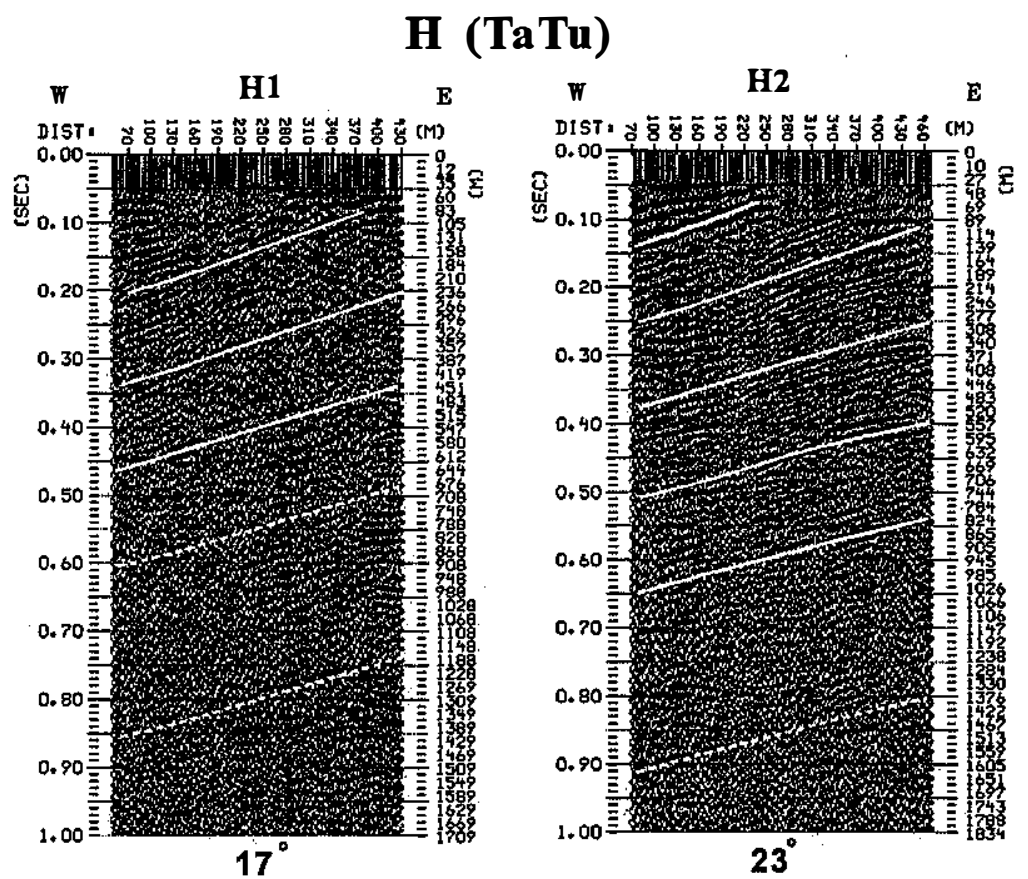

\section{I (TaTuHsi)}

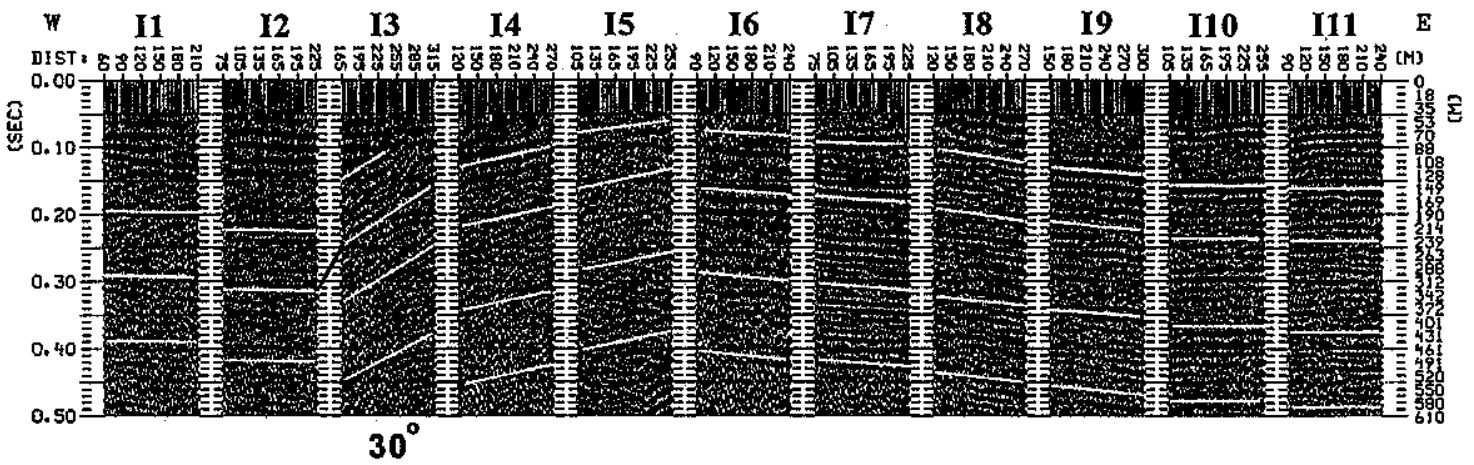

Fig. 12. Profile $\mathrm{H}$ (top) contains two sections ( $\mathrm{H} 1$ and $\mathrm{H} 2$ ) located directly at the position of the suspected Changhua fault north of the Tatuhsi river. The bending of the layers is quite clear, with dip angles greater than 15 degrees. Profile I (bottom) is a consecutive section profile made along the southern bank of the Tatuhsi river. A fault-bend-fold structure sits in the middle, which has a step front with a dip angle of more than 25 degrees and an anticline at the back. This high angle indicates that the axis of TatuPakua anticline may reach its climax at the position of the Tatuhsi river. 

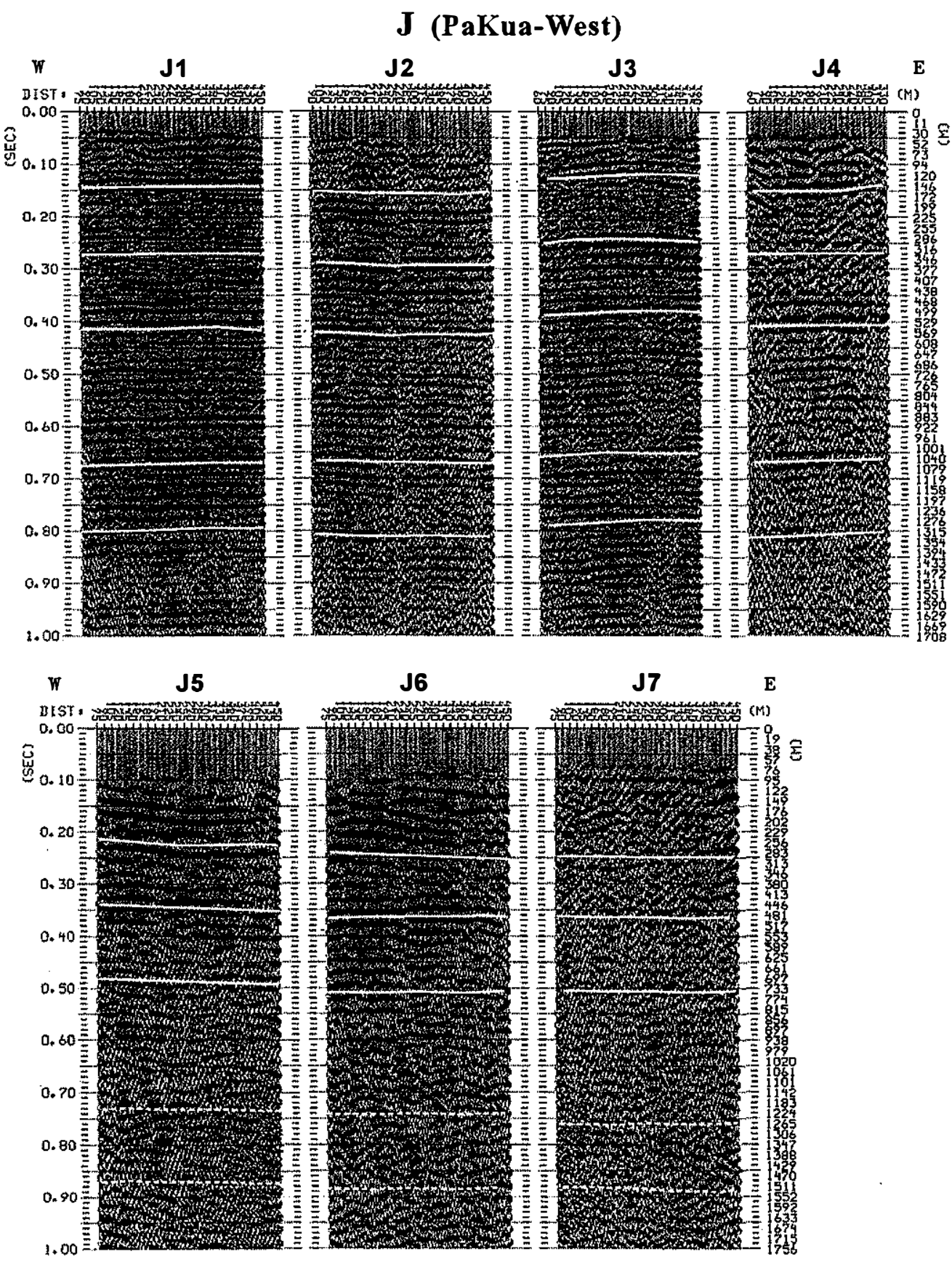

Fig. 13. Prof ile $\mathrm{J}$ consists of seven sections made in the plain area along the Changhua fault positions proposed by the CPC (Fig. 1). The structural layers were very flat, which exclude the existence of the fault in the plain area. 
K (PaKua-East)
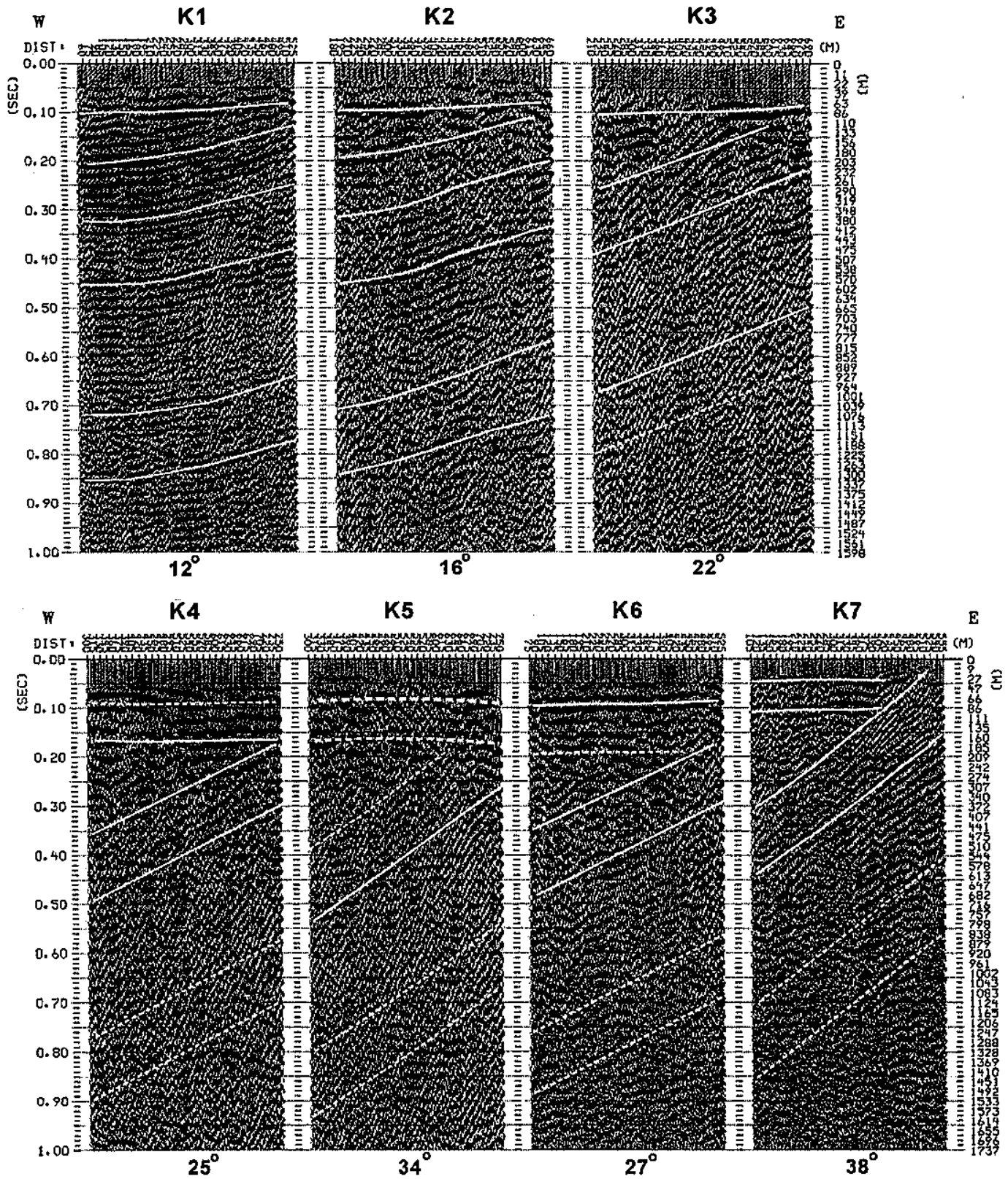

Fig. 14. The seven sections along the western border of the Pakua terrace scarps. Check Fig. 5b for locations. The K7 and J5 lines in Fig. 13 are actually aligned. They show a gradual uplifting of layers from flat to steep. The bending of the structures is steeper toward the south, which implies a higher level of activity in the southern part of the Changhua fault. 
deep gravel deposits. We need be more conservative when interpreting them. Nevertheless, these sections can still give us the general dipping features of the layers. It is interesting that the bending angles of the layers may increase from north to south. This strongly implies that the southern portion of the Pakua terrace suffered greater compression. The Tienchung culmination has been postulated to exist by Chang (1971) at the southern part of the Pakua terrace (see Fig. 3). This is not unexpected since the Peikang basement high is directly west of the Pakua terrace (Fig. 1). It is also in agreement with the fact that in the southern part, the axis of the Pakua anticline shifts to the west (Fig. 5b). Figure 14 provides the important information that the southern Pakua terrace is largely distorted and may quite possibly be an active fault. It now becomes understandable why the epicenter of the 1999 Chichi earthquake was located at Chichi, which is only $20 \mathrm{~km}$ to the east along the Choshuihsi river. The region along the Choshuihsi river may have suffered great tectonic compressions from the east due to its right geographic position with respect to the Peikang High.

\section{DISCUSSION AND SUMMARY}

The reflection seismic sections in this paper provide us with a different insight into the Changhua fault as well as the three terraces in west-central Taiwan. Some of these observations have never been reported before. The new findings are: 1) a hidden NE-SW Tai-an fault bisects the three terraces into northern and southern portions; 2) the northern portion is relatively flat, except for some layers slightly tilting along the expected Changhua fault positions; 3) the suspected accompanying Tiehchanshan-Hengshan backthrust fault, although having apparent geomorphologic lineation, may not exist in deeper places; 4) there is an almost quiet zone along the path of the Tai-an fault near Shalu, which could be a result of mutual interaction with the Changhua fault; 5) the main trace of the Changhua fault could turn east at Lungjing, which opens the Nansukeng depression area; 6) the southern portion contains two structural highs, the Tatuhsi and Tienchung culminations, with the Tatuhsi culmination being a split ridge through which the Tatuhsi river now flows; 7) greater layer bending was found in the south, which indicates that there is higher compression on the southern portion of the Pakua terrace.

Delcaillau et al. (1998) and Delcaillau (2001) have used geomorphologic methods to study the Pakua and Tatu terraces. They attributed the evolution of these terraces to a late Quaternary uplift $(0.5 \mathrm{Ma})$ of the front thrust belt of Taiwan's western foothills. The Pakua terrace grew as a lateral propagation (westwards and southwards) of active anticlines, which had greater deformation in the south where a fault-propagation-fold may have formed. For the Tatu terrace, Delcaillau (2001) proposed a three stage development from the coalescing of three independent segments. However, we think this might be overcomplicated. The drainage system and the landform variations are in relatively lower amplitude on the Tatu terrace, compared to the Pakua terrace. The structures north of the Tai-an boundary are flat and could be a region of 'low activity'. By contrast, the southern portion is under wider conflict and variation.

Lee et al. (1996) used paleostress analysis to examine the fault systems in the Pakua and Tatu terraces. They proposed an interesting model: two NW trending transfer faults, which 
can explain the normal faults found in the northern Pakua terrace (Fig. 9 in Lee et al. 1996). Sung and Chen (2003) further attributed these transfer faults to an oblique ramp of the Peikang High, on which the Changhua fault developed. Systematic varying morphological features found on the Paku terrace may confirm this kinematic model. The positions of these two transfer faults do match the winding shape of the Changhua fault found by us, i.e., there are two bends at Huatan and Lungjing (Fig. 1). A shear system may have developed parallel to the Tatuhsi river (or Wuhsi river), which also could cause the Chelungpu fault to tum near Wufeng.

To conclude, we suggest that the Tai-an fault boundary could be the EW transverse structure that people have been searching for around the Ta-anhsi and Tachiahsi rivers (Meng 1965; Wang 2002). The Tai-an fault could provide the blockage that caused the northern portion to be less affected by the Changhua fault. The southern portion, on the contrary, may be subject to great tectonic impact, so its structures are highly distorted, even producing transfer faults to adjust the oblique interactions among the different systems. A high potential for significant earthquakes may exist in the south, especially the southern Pakua terrace. This result is consistent with the conclusions of many other researches, and should be investigated further.

Acknowledgments This research was supported by the National Science Council under grants NSC90-2116-M-008-003 and NSC91-2116- M008-002. Although these grants mostly financed the Chelungpu fault studies, we shared the budget to cover the western side of the fault. The large amounts of labor contributed by many undergraduate and graduate students during the field work are highly appreciated. We wish to think the CPC for kindly providing the seismic sections which constitute the foundation of this research.

\section{REFERENCES}

Chang, C. C, 1994: Geologic map of Taiwan: Tachia (1:50,000), Cent. Geol. Surv., MOEA, Taiwan.

Chang, J. C., and G. S. Yang, 2001: Distribution and geomorphic characteristics of active fault in central Taiwan. Geograph. Res., 35, 85-120.

Chang, S. S. L., 1971: Subsurface geological study of the Taichung basin, Taiwan. Petro. Geol. Taiwan, 8, 21-45.

Chen, J. S., 1978: A Comparative Study of the Refraction and Reflection Seismic Data Obtained on the Changhua Plain to the Peikang Shelf, Taiwan. Petrol. Geol. Taiwan, 15, 199-217.

Chen, M. M., and H. C. Ho, 2000: Correlation between Chi-Chi earthquake ruptures and the Chelungpu fauilt. CGS Special Issue, 12, 113-138.

Chen, T. S., and F. C. Su, 2002: Structural pattern of the northern portion of the Changhua fault. Conference of Earth System Sciences, Chungli, Taiwan, G-133-142.

Central Geologic Survey, 2001: An Introduction to the Active Faults in Taiwan, 2nd edi., Cent. Geol. Surv., MOEA, Taiwan.

Chinese Petroleum Corporation, 1982: The geological map of Miaoli, Taichung and Chiayi, Taiwan Petrol. Explor. Div. Publ., CPC, Taiwan, scale 1:100,000. 
Chiu, H. T., 1975: Miocene stratigraphy and its relation to the paleogene rock in west-central Taiwan. Petro. Geol. Taiwan, 12, 51-80.

Chou, J. T., 1971: A sedimentological and paleogeographic study of the Neogene formations in the Taichung region, western Taiwan. Petrol. Geol. Taiwan, 9, 43-86.

Delcaillau, B., B. Deffontaines, L. Floissac, J. Angelier, J. Deramond, P. Souquet, H. T. Chu, and J. C. Lee, 1998: Morphotectonic evidence from lateral propagation of an active frontal fold; Pakuashan anticline, foothills of Taiwan. Geomoph., 24, 263-290.

Delcaillau, B., 2001: Geomorphic response to growing fault-related folds: example from the foothills of central Taiwan. Geodina. Acta, 14, 265-287.

Ho, C. S., 1988: An introduction to the geology of Taiwan: explanatory text of the geology map of Taiwan, Cent. Geol. Surv., MOEA, Taiwan, 192pp.

Hsiao, J. W., 2002: Investigating the shallow structures around the Chinshui fault, westcentral Taiwan, M. S. thesis, National Central University, Chungli, Taiwan.

Hsiao, P. T., 1968: Seismic study of the Taichung area, Taiwan. Petro. Geol. Taiwan, 6, 209216.

Hsu, W. L., 2001: Detecting the Changhua Fault and its Neighboring Structures, M. S. thesis, National Central University, Chungli, Taiwan.

Hu, C. C., and H. T. Chiu, 1984: Deep structure of the Cholan area, northwestern Taiwan. Petro. Geol. Taiwan, 20, 21-33.

Hung, J. H., and K. Wiltschko, 1993: Structure and kinematics of arcuate thrust faults in the Miaoli-Cholan area of western Taiwan. Petro. Geol. Taiwan, 28, 59-96.

Lee, J. C., C. Y. Lu, H. T. Chu, B. Delcaillau, J. Angelier and B. Deffontaines, 1996: Active deformation and paleostress analysis in the Pakua anticline area of estern Taiwan. TAO, 7, 431-446.

Lee, J. C., H. T. Chu, J. Angelier, Y. C. Chan, J. C. Hu, C. Y. Lu, and R. J. Rau, 2002: Geometry and structure of northern surface ruptures of the $1999 \mathrm{Mw}=7.6 \mathrm{Chi}$-Chi Taiwan earthquake: influence from inherited fold belt structures. J. Struc. Geol., 24, 173-192.

Meng, C. Y., 1963: The San-I overthrust. Petro. Geol. Taiwan, 2, 1-20.

Meng, C. Y., 1965: Lateral movement in the northern half of western Taiwan. Proc. Geol. Soc. China, 4, 89-95.

Mouthereau, F., O. Lacombe, B. Deffontains, J. Angelier, H. T. Chu, and J. C. Lee, 1999: Quaternary transfer faulting and belt front deformation at Pakuashan (westernTaiwan). Tectonics, 18, 215-230.

Pan, Y. S., 1967: Interpretation and seismic coordination of the Bouguer gravity anomalies over west-central Taiwan. Petro. Geol. Taiwan, 5, 99-115.

Shih, T. T., K. H. Teng, J. C. Chang, C. D. Shih, and G. S. Yang, 1986: A geomorphological study of active faults in Taiwan. Geograp. Res., 12, 1-44.

Sun, S. C., 1965: Geology and Petroleum Potentialities of theChingshui-Yuanlin Area, Taiwan. Petrol. Geol. Taiwan, 4, 161-173.

Sung, Q. C., and Y. C. Chen, 2003: Geomorphic evidence and kinematic model for the Quaternary transfer faulting of the Pakuashan anticline, central Taiwan. J. Asian Earth Sci., 
(in press).

Suppe, J., 1981: Mechanics of Mountain Building and Metamorphism in Taiwan. Memoir. Geol. Soc. China, 4, 67-89.

Suppe, J., and J. Namson, 1979: Fault-bend origin of frontal folds of the western Taiwan foldand-thrust belt. Proc. Geol. Soc. China, 16, 1-18.

Tsai, Y. B., 1985: A study of disastrous earthquakes in Taiwan, 1683-1895. Bull. Ins. Earth Sci., Academia sinica, 5, 1-44.

Wang C. Y., J. D. Chiu, and L. A. Lin, 2001: The detection of three active faults on the Taoyuan Terrace, northwestern Taiwan by the shallow reflection seismic method. TAO, 12, 599-614.

Wang, C. Y., 2002: The detection of a recent earthquake fault by the shallow reflection seismic method. Geophysics, 67, 1465-1473.

Yang, C. Y., 1972: Note on the subsurface unconformity in the Pakuashan area. Petro. Geol. Taiwan, 10, 179-186. 